\title{
Souvenirs de Michèle Therrien
}

\section{Guy Bordin}

\section{CpenEdition}

Journals

Édition électronique

URL : https://journals.openedition.org/jsa/17026

DOI : 10.4000/jsa. 17026

ISSN : $1957-7842$

\section{Éditeur}

Société des américanistes

\section{Édition imprimée}

Date de publication : 15 juin 2019

Pagination : 187-190

ISBN : 978-2-902715-11-4

ISSN : 0037-9174

\section{Référence électronique}

Guy Bordin, "Souvenirs de Michèle Therrien », Journal de la Société des américanistes [En ligne], 105-1 | 2019, mis en ligne le 15 juin 2019, consulté le 04 septembre 2022. URL : http:// journals.openedition.org/jsa/17026; DOI : https://doi.org/10.4000/jsa.17026 


\title{
Souvenirs de Michèle Therrien
}

\author{
Guy BORDIN *
}

Lundi 21 octobre 1996: rentrée universitaire en $1^{\text {re }}$ année de langue et culture inuit à l'Inalco, dans la classe de Michèle Therrien. Je découvre la femme avec laquelle je me suis déjà longuement entretenu au téléphone. Elle est vive et menue, longs cheveux noirs tombant sur les épaules. Je suis à ce moment loin d'imaginer que nous deviendrons si proches pendant tant d'années.

Je lui avais écrit quelques mois plus tôt que je voulais étudier la langue inuit. Cependant, parce que je vivais à Bruxelles, je ne pouvais assister aux cours qu'une semaine sur deux. Elle me proposa une méthode de travail qui fonctionna sans difficulté, malgré un surcroît de travail pour elle. La semaine où je ne venais pas à Paris, elle m'envoyait un résumé de ce qu'elle avait exposé en cours, un corrigé de mes exercices et ceux à faire pour la séance suivante. Ce qu'elle fit pour moi, elle le fit pour d'autres, car elle voulait que toute personne désireuse de le faire puisse étudier la langue inuit.

J'ai immédiatement apprécié les cours de Michèle qui savait créer une ambiance studieuse et décontractée. Spécialiste d'une culture de l'oralité, elle était elle-même une grande oratrice et une excellente conteuse, possédant admirablement l'art de captiver son public. Elle truffait ses leçons d'anecdotes, souvent liées à ses expériences personnelles. Son empathie profonde pour le monde inuit était communicative, mais elle savait faire la part des choses et combattait par exemple les thèses essentialistes si souvent prisées lorsque l'on parle des peuples dits autochtones.

Michèle Therrien était une enseignante exigeante, qui s'investissait sans limite dans sa tâche, qu'elle concevait comme une mission, et qui en retour attendait beaucoup de ses étudiants. Elle avait raison, car la langue inuit est difficile, et son étude demande discipline, rigueur, volonté et, avant tout, humilité. Elle insistait sur le fait d'apprendre des textes par cœur et de les restituer à

* Centre d'étude et de recherche sur les littératures et les oralités du monde (INALCO) [guybordin@skynet.be]. 
voix haute, excellente façon de fixer, entre autres difficultés, certaines formes grammaticales peu commodes.

Michèle souhaitait que ses étudiants réussissent, elle soutenait toutes les initiatives allant en ce sens, et elle-même en initia de nombreuses. J'en mentionnerai trois qui ont eu un impact profond sur mon implication dans le monde des études inuit.

$$
* * *
$$

En septembre 1998, Emmanuelle Stimamiglio - également étudiante en langue inuit - et moi, nous rendîmes au Groenland afin de tourner un courtmétrage documentaire sur les rapports hommes-animaux dans cette société. Nous séjournâmes deux semaines à Ilulissat, puis une semaine à Nuuk pour assister avec Michèle au XI ${ }^{\mathrm{e}}$ Congrès d'études inuit. À notre retour, Michèle nous fit bénéficier des services du Centre de ressources pédagogiques audiovisuelinformatique-multimédia de l'Inalco pour la post-production de notre film et, en particulier, des talents du monteur Guy Sinelle ${ }^{1}$. Terminé en juillet 2000, Une fin d'été au Groenland, mon premier film, m'a montré une voie que j'ai depuis suivie plus intensément en coréalisant huit films avec le réalisateur Renaud De Putter, dont trois chez les Inuit du nord de la Terre de Baffin ${ }^{2}$.

Au début des années 1990, Michèle Therrien et Susan Sammons (19532011) - alors responsable du programme d'études inuit du Collège arctique du Nunavut (NAC) à Iqaluit, avaient institué un système d'échanges entre les deux institutions. Chaque année, un étudiant inuit venait à Paris pendant plusieurs semaines pour enseigner sa langue, et un étudiant de l'Inalco se rendait à Iqaluit pour travailler avec les étudiants du NAC et, souvent, s'initier au travail de terrain. Au total, une trentaine d'étudiants inuit et français ont pu bénéficier de ce programme. Ce fut mon cas pendant le mois d'avril 2000. Deux ou trois fois par semaine, j'encadrais un petit groupe d'étudiantes dans leurs travaux de rédaction de dossiers thématiques liés à la culture inuit. En parallèle, j'ai pu approfondir le travail sur le lexique anatomique inuit ${ }^{3}$ que j'avais commencé l'année précédente sur la base d'une première compilation terminologique faite par Michèle dans son ouvrage Le corps inuit (1987).

1. Il venait lui-même de terminer le montage du film de Michèle, Printemps inuit au Nunavut (1999).

2. J'ai rêvé (2006), Circe's Place (2011), Les Maisons du Nord (2015). L'une des premières projections publiques de $J^{\prime}$ 'ai rêvé eut lieu en octobre 2006 au musée du quai Branly à Paris qui accueillait alors son premier événement international, le $X V^{e}$ Congrès d'études inuit organisé par Michèle Therrien, Nicole Tersis et Béatrice Collignon.

3. Ce qui conduisit à la publication de mon livre Lexique analytique de l'anatomie humaine (inuktitut-français-anglais) (2003), grâce à l'ethnologue et éditeur Vladimir Randa, chargé de cours à l'Inalco à l'époque. 
Après 1'obtention de mon diplôme supérieur en langue et culture inuit en 2001, je me suis lancé dans une thèse de doctorat, naturellement sous la direction de Michèle, qui m'associa très chaleureusement aux travaux du groupe de recherche sur l'anthropologie de la nuit auquel elle participait, fondé quelques années plus tôt par Aurore Monod Becquelin et Jacques Galinier à l'université Paris X (Nanterre).

Ce groupe - initialement créé par des chercheurs travaillant au sein de populations vivant aux latitudes moyennes, tropicales et équatoriales - a mené, dès ses origines, un questionnement sur les réponses fortement contrastées apportées sur les cinq continents à l'alternance des deux segments du cycle jour-nuit. L'arrivée de Michèle Therrien permit d'intégrer à la réflexion comparative les vécus et représentations de populations installées à des latitudes arctiques, où les alternances saisonnières et quotidiennes obscurité-lumière et nuit-jour sont phénoménologiquement d'une autre nature. Pour réaliser leur programme, les membres du groupe des « Nocturnes » devaient produire de l'ethnographie dans un domaine où les données étaient lacunaires et sortir la nuit de son sort « d'insaisissable réservé à la sphère de l'intime et du subjectif », pour reprendre une belle expression de Michèle prononcée lors de la soutenance de ma thèse.

Je suis parti à la fin 2001 au Nunavut pour un premier terrain consacré à la nuit. Dès 2002, je pus - en présence de Michèle - présenter mes lignes de recherche et quelques données brutes issues de cette première phase à un public international. Ma communication intervint à Nuuk dans le cadre de la toute nouvelle International Ph.D. School for Studies of Arctic Societies (IPSSAS), dont Michèle Therrien fut un membre fondateur. Je soutins ma thèse à Nanterre en 2008, devant un jury qui rassemblait des anthropologues « nocturnes » et des spécialistes des études inuit.

Pendant toutes ces années, Michèle et moi participâmes ensemble aux séances du séminaire de la nuit, puis elle me laissa poursuivre seul. Avec la générosité qui la caractérisait, elle considéra à un certain moment que la nuit inuit était devenue «mon » sujet. Cela se produisit peu après la publication en $2010 \mathrm{de}$ l'article collectif « Anthropology of the night. Cross-disciplinary investigations », cosigné par dix auteurs dont elle et moi (Galiner et al. 2010).

$$
* * *
$$

Ces trois exemples, issus de mon parcours personnel, montrent le dévouement de Michèle vis-à-vis de ses étudiants, dont bien d'autres pourraient apporter d'innombrables témoignages. Je ne puis, pour ma part, que lui rester infiniment reconnaissant de m'avoir permis de prendre part à cette aventure fascinante, toujours en cours. 
Guy BORDIN

Ensuite, nos chemins ont cessé de se croiser pour diverses raisons. Notre ultime rencontre eut lieu en 2014 au Québec, son pays natal et de cœur, à l'occasion du XIX ${ }^{\mathrm{e}}$ Congrès d'études inuit.

Taimaittuq, « c'est ainsi », dit-on en inuktitut.

\section{Références citées}

BORDIN Guy

2003 Lexique analytique de l'anatomie humaine (inuktitut-français-anglais), Peeters/ SELAF (Arctique, 6), Louvain/Paris/Dudley.

Galinier Jacques, Aurore Monod Becquelin, Guy Bordin, Laurent Fontaine, Francine Fourmaux, Juliette Roullet, Piero Salzarulo, Philippe Simmonot, Michèle THERRIEN et Iole ZILLI

2010 " Anthropology of the night. Cross-disciplinary investigations », Current Anthropology, 51 (6), p. 819-847. 